\section{GYGES E A TIRANIA DO ANEL: ANÁLISE DA PASSAGEM 359B-362C DA REPÚBLICA DE PLATÃO}

\author{
Luiz Maurício Bentim da Rocha Menezes*
}

RESUMO: Gyges foi o primeiro tirano a reinar na Lídia pela casa dos Mermnadas por volta do séc. VII a. C. Ele foi também o primeiro grande bárbaro com o qual os gregos estabeleceram contato. Em Platão, Gyges aparece ligado à narrativa de Gláucon no Livro II da República (359b-360b), onde este conta os feitos daquele para se tornar o soberano da Lídia. Há uma dificuldade na passagem 359d que faz com que a identificação direta de Gyges com a narrativa de Gláucon seja prejudicada. Pretendemos através deste trabalho (I) apresentar algumas propostas de interpretação para a passagem, utilizando para isso não só o texto de Platão como as fontes líricas e históricas anteriores a ele; e (II) analisar a relação de Gyges com a tirania, perpassando pelo tema da justiça e da injustiça que são centrais na República. Com isso se pretende demonstrar que a narrativa de Gláucon é uma narrativa sobre a tirania, um problema importante para a filosofia política de Platão e que deverá ser resolvido por Sócrates.

PALAVRAS-CHAVE: República de Platão; anel de Gyges; tirania; justiça; injustiça.

\section{GYGES AND TYRANNY OF THE RING: ANALYSIS OF THE PASS AGE 359B-362C OF PLATO'S REPUBLIC}

\begin{abstract}
Gyges was the first tyrant, of the Mermnadae's lineage, around the seventh century BC in Lydia. He was also the first great barbarian to whom the Greeks made contact to. Gyges appear in Glaucon's narrative in Book II of Plato's Republic (359b-360b), which talks about his deeds to become the sovereign of Lydia. However, one difficulty on the passage $359 \mathrm{~d}$, which makes a direct identification of Gyges with the narrative, has been mistaken. This paper aims (I) to present some proposals to the passage mentioned using, not only Plato's text, but the lyric and historical sources before him, and (II) to analyze Gyges' relation with the tyranny, considering the theme of justice and injustice, which is central to the Republic itself. Thus, the paper intends to demonstrate that Glaucon's narrative is one on tyranny, therefore, an important problem for Plato's political philosophy which shall be solved by Socrates.
\end{abstract}

KEYWORDS: Plato's Republic, Gyges’ Ring; Tyranny; Justice; Injustice.
* Professor de Filosofia Antiga da Universidade do Estado do Amapá (UEAP). Doutorando em Filosofia pelo PPGLM/UFRJ. lmbrmenezes@ yahoo.com.br 
G yges é um nome conhecido da antiga Lídia, além de ser o principal personagem da linhagem dos Mermnadas. Sardis foi a principal cidade da Lídia e teve seu apogeu político, cultural e econômico na era da dinastia Mermnadas entre os séculos VII e VI a.C. Os Mermnadas iniciaram seu governo com a subida de Gyges ao poder e o terminaram com a queda de Creso pelos persas. A partir de uma análise dos registros feitos pelos antigos sobre Gyges, pretendemos demonstrar seu caráter complexo, que fez com que se desenvolvessem diversas histórias a seu respeito, sendo a mais famosa aquela que conta a maneira como ele chegou ao poder. Sua fama percorreu o mundo grego influenciando tanto seus contemporâneos como aqueles que vieram posteriormente.

\section{FonTES SOBRE Gyges}

A lírica grega desenvolvida entre os séculos VII e VI deixou, nos fragmentos que nos restaram, um precioso tesouro a respeito de Gyges da Lídia. A primeira fonte que temos a seu respeito é de Arquíloco de Paros, que assim nos fala sobre ele:

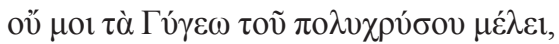

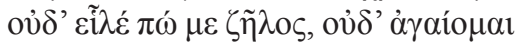

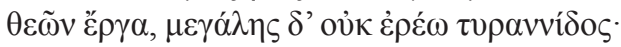

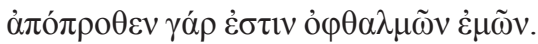

Não me preocupam as coisas de Gyges, rico em ouro,

Nem ainda me persegue a cobiça, nem invejo

As obras dos deuses, ou amor pela grande tirania;

Isto longe está dos meus olhos. (Fr. 19W) ${ }^{1}$

Arquíloco, que viveu entre 680-640 a.C., ${ }^{2}$ foi contemporâneo de Gyges, que teria reinado entre 682-644 a.C. ${ }^{3}$ Tal fragmento, dos que nos chegaram, além de ser o primeiro a tratar de Gyges, parece também ter sido o primeiro a utilizar no grego o termo "tirania". Segundo Ure, a palavra tirania não é grega, mas pode ser de origem lídia (1922, p.134). Para Adrados, a palavra designa o poder absoluto dos monarcas orientais (1990a, nota 2, p. 54). De acordo com Euphorion (séc. III a.C.), Gyges foi o primeiro a ser chamado de tirano. ${ }^{4}$

\footnotetext{
${ }^{1}$ O fragmento foi retirado da edição de West (1971). A tradução dos fragmentos citados nesse artigo é nossa.

${ }^{2}$ Para a data aproximada de Arquíloco nos baseamos em Jacoby (1941).

${ }^{3}$ A data comumente aceita pelos estudiosos é de 687-652 a.C., principalmente depois dos estudos de Gelzer (1875). No entanto, concordamos com os estudos de Spalinger (1978). Spalinger em seu texto aponta para o fato de que a morte de Gyges só é apontada no Prisma A dos anais de Assurbanipal. Tal Prisma data de 643/2 a.C., o que faz Spalinger calcular a morte de Gyges por volta de 644 a.C. Para calcular a data inicial de seu reinado, nos baseamos na duração dita por Heródoto do reinado de Gyges, trinta e oito anos.

${ }^{4}$ Fr.1 de Müller (1849, p. 72). Demais citações de Müller serão abreviadas por FHG, indicando-se em seguida volume e fragmento.
} 
Tal declaração pode ser apenas uma inferência de Hípias de Élis, que disse não ter Homero

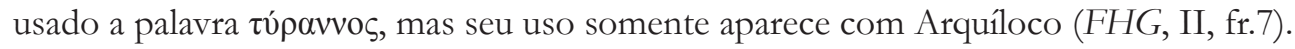

O fr. 19W indica o poder de Gyges, entre riqueza e posses, que faz dele o senhor da Lídia e tirano da Ásia. Apesar de o poema estar na primeira pessoa, sabemos que Arquíloco não se coloca como falante, mas atribui o dito ao personagem Kháron, conforme nos informa Aristóteles:

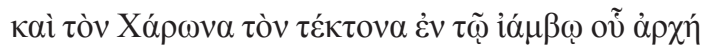

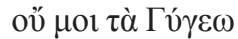

e Kháron, o carpinteiro, em iambo, assim começa:

Não a mim as coisas de Gyges (Arte Retórica, 1418b30-31) ${ }^{5}$

O uso de uma personagem para dizer algo sobre outro é um método original da crítica de Arquíloco. Segundo West, há um particular tipo de poesia que os antigos chamam de iambo para usar personagens e situações imaginários (1974, p. 22-39).

Outros poetas líricos anteriores a Heródoto comprovam a historicidade de Gyges sendo estes Álcman' (fl. 652 a.C.), Mimnermo (fl. 632 a.C.) e Hipônax (Fr. 42W) (fl. 540 a.C.). É interessante notarmos que Mimnermo compôs versos elegíacos da batalha entre Esmirna contra Gyges e os Lídios, e parece ter escrito uma Esmirneida, infelizmente perdida (Fr. 13W e Fr.13aW). Também podemos encontrar um poema referente a Anacreonte que muito se parece como o que Arquíloco escreveu a respeito de Gyges (Fr. 8W). ${ }^{7}$

Ressaltamos que o que aqui se diz de Anacreonte foi produzido posteriormente à morte do poeta no período helenístico e atribuído ao poeta de forma pseudepigráfica. Esse material se encontra reunido na obra conhecida como Anacreontea. De qualquer maneira, estes, assim como os demais fragmentos dos outros poetas, demonstram a repercussão do lídio Gyges entre os gregos.

Heródoto nos conta a história de Gyges da seguinte maneira (Histórias, I.8-15): ${ }^{8}$ Candaules, o soberano da Lídia, oferece a Gyges, seu guarda pessoal, a permissão para que este veja sua mulher nua e, assim, possa comprovar que ela é a mais bela de todas. Pois, segundo diz Candaules, "os homens confiam menos em seus ouvidos do que em seus olhos" (Hdt. I.8.2). Mesmo dizendo-se persuadido pelas palavras de Candaules, de que sua mulher é a mais bela, Gyges é obrigado a ver para comprovar tal fato. Escondido atrás da porta do quarto, Gyges vê a rainha nua e, quando se preparava para se retirar, acabou sendo visto por ela sem que ele assim percebesse. Entendendo o ocorrido e percebendo que se tratava de obra de Candaules, a rainha nada fala e aguarda. No dia seguinte, a rainha chama Gyges em sua presença e apresenta a ele dois caminhos: ou mata o soberano ou morre

\footnotetext{
${ }^{5}$ Utilizamos a edição de Ross (1959). A tradução é nossa.

${ }^{6}$ Greek Anthology, VII.709.1-6.

${ }^{7}$ Edição de West (1984).

${ }^{8}$ Utilizamos o texto estabelecido por Hude (1927).
} 
(Hdt. I,11.2-3). Para evitar a morte, Gyges escolhe matar o soberano e assim toma para si a mulher e a soberania (Hdt. I,12.2).

Há também a versão de Xanto, que embora fosse lídio, escreveu em grego. Este pode ter vivido em Sardis, embora Estrabão (13.4.9) ${ }^{9}$ não tenha certeza. Tinha o pai lídio ${ }^{10} \mathrm{e}$ a mãe talvez fosse de origem grega. Sua Lydiaká (Relatos da Lidia) foi composta de anedotas, etimologias, mitos, geologia, além de apresentar extraordinárias histórias sobre os primeiros reis da Lídia (PEDLEY 1972, p. 2). O problema é que sua obra foi perdida, restando-nos apenas citações que foram feitas por pensadores posteriores. Nicolau Damasceno, que viveu por volta do séc. I a.C., reuniu a obra de Xanto, relatando a história de Gyges no Livro VI de sua História Universal, da qual só nos sobraram alguns fragmentos. Apesar de ser uma fonte tardia sobre Gyges, Nicolau Damasceno parece ter seguido a Lydiaká de Xanto, o lídio, que viveu na mesma época de Heródoto. A versão de Damasceno, apesar de ter algumas diferenças, parece apoiar a tese da usurpação do trono por Gyges. ${ }^{11}$

Segundo Heródoto (I.7), Candaules faria parte da família dos Heraclidas e seria conhecido pelos gregos pelo nome de Mirsilos. Os Heraclidas teriam governado a Lídia por vinte e duas gerações ou 505 anos. Segundo o poeta Hipônax (Fr. 1), ${ }^{12}$ Candaules seria um nome meônio para o deus Hermes. Isso dá base à hipótese de Pedley de que os Heraclidas seriam os meônios de Homero, que teriam invadido Sardis por volta de 1200 a.C., entre o final da Idade de Bronze e o começo da Idade de Ferro. Por outro lado, os Mermnadas seriam autóctones que retomariam o poder com Gyges no séc. VII a.C (Pedley, 1968, p. 34). ${ }^{13}$ No entanto, Bolling aponta para a possibilidade de que ao invés de ser um nome meônio, Candaules possa ser o nome lídio para Héracles. ${ }^{14}$

No Livro II da República, Platão, através de seu personagem Gláucon, irá nos contar a narrativa de Gyges e de como ele encontrou seu anel de ouro. ${ }^{15}$ Através do uso desse anel, Gyges irá usurpar o trono da Lídia, matando seu soberano, e irá se tornar o primeiro tirano.

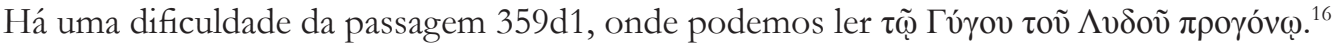
Os estudiosos se dividem basicamente em dois grupos quando nos referimos a tal passagem

\footnotetext{
${ }^{9}$ Utilizamos a edição de Jones (1924).

${ }^{10}$ Suidas, s.v. $\Xi \alpha ́ v \theta 0$.

${ }^{11}$ A parte que fala de Gyges pode ser encontrada no FHG, III, fr.49, p. 380-386; e no FGrHist 90 F44-47.

12 Utilizamos a edição de Bergk (1882).

${ }^{13}$ Ver também a hipótese de Hanfmann (1958, p. 68-72) para a história de 'Masnes e Tylos'.

${ }^{14}$ Ver Bolling (1927, p. 15). Isso iria contra a hipótese de se pensar os Mermnadas como autóctones, pois, segundo Bolling (1927, p. 16): "Este deus se tornou o fundador da dinastia lídia, cujos membros os gregos chamam Heraclidas, tendo identificado Candaules com Héracles".

${ }^{15}$ República, 359b-360b. Utilizamos aqui a tradução de Pereira (2001). Tomaremos esta tradução como base para nosso trabalho, indicando outras, inclusive nossas, quando for o caso.

${ }^{16}$ Utilizamos aqui o texto grego da República estabelecido por S. R. Slings, Platonis Rempvblicam (2003). Slings utiliza o sinal † entre o começo e o fim da passagem para indicar uma possível corrupção do original grego, o que nos leva a uma dificuldade para relacionar a quem estaria Platão, de fato, falando.
} 
estudada. O primeiro grupo se refere ao comentário de Adam à República, ${ }^{17}$ no qual este defende que o antepassado vem a ser do Lídio Gyges. Já o segundo grupo defende que Gyges é o antepassado do Lídio. Resolvemos ${ }^{18}$ o problema da passagem através da sugestão de Slings que assim coloca como passagem original: $\Gamma$ ṿ́ $\tau \tilde{\varphi} \Lambda v \delta \tilde{\omega}$. Dessa forma, entraria em harmonia com a passagem $612 \mathrm{~b}$, mantendo Gyges como único possuidor do anel no texto platônico, assim como também estaria de acordo com a posterior inclusão do termo $\tau \tilde{\varphi}$ $\pi \rho$ ớv $\omega$ sem prejuízo para a interpretação da passagem $359 \mathrm{~d} \cdot{ }^{19} \mathrm{Em}$ nossa pesquisa, pudemos constatar que toda a tradição que utiliza o termo "anel de Gyges” é posterior a Platão. ${ }^{20}$

\section{Gyges, O ANEL E A TIRANIA}

Podemos perceber que a construção da figura de Gyges associada à tirania e a riqueza exacerbada começa a ser formada desde a época de Arquíloco e é posteriormente fortalecida por outros líricos. Gláucon ao fazer a defesa da injustiça está demonstrando no decorrer de seu discurso que é a vida do tirano que os muitos (polloí) têm em mente quando fazem seu elogio da injustiça. Sendo assim, Gláucon continuará a explorar em seu argumento (Rep., 360d8-362c6) o que foi dito sobre a vida justa e injusta, assim como os efeitos da dýnamis do justo e do injusto na alma do homem. Para isto, Gláucon irá considerar cada um separadamente, o mais justo (dikaiótaton) do mais injusto (adikótaton), tomandoos como completos em suas maneiras de viver (Rep., 360e). Tal estratagema servirá para reforçar o seu desafio a Sócrates de provar a dýnamis da justiça na alma, já que, se a natureza humana é voltada para a pleonexía, ${ }^{21}$ um homem não poderia ser justo por vontade própria.

${ }^{17}$ Cf. Adam, 1979, p. 126-7, apêndice I do livro II.

${ }^{18}$ Ver Menezes, 2012, p. 29-39.

${ }^{19}$ Feitas as modificações, o texto poderia ser assim traduzido: "terem a capacidade que se diz ter sido concedida a Gyges, o Lídio" ou com a posterior inclusão dos termos “ao antepassado lídio, Gyges”. ${ }^{20}$ Para a tradição posterior que seguiu a história de Platão do anel de Gyges, sem pretensão de exaurir a questão, colocamos aqui todas as fontes que encontramos a partir de nossas pesquisas: Luciano. Bis accusatus sive tribunalia, 21; Id. Navigium, 42; Socraticorum Epistulae. Ep., 14.2; Joannes Stobaeus. Anthologium, III.9.63; Libanius. Epistulae, 432.5; Id. Orationes, 56.10; Ibid., 64.35; Gregorius Nazianzenus. Contra Julianum imperatorem (orat. 4), 35.628; Id. Funebris oratio in laudem Basilii Magni Caesareae in Cappadocia episcope (orat. 43), 21.3; Id. Carmina moralia, 683; Id. Carmina de se ipso, 1435; Philostratus. Vita Apollonii, 3.8; Id. Heroicus, 669; Anônimo. In Aristotelis artem rhetoricam commentarium, (CAG, 21.2) 256.6; Theon. Rhet. Graeci, I.159; Tzetzes. Chiliades, I.137-66; Ibid., VII.195-202; Nonnus. Invect., 1.55; Anônimo.

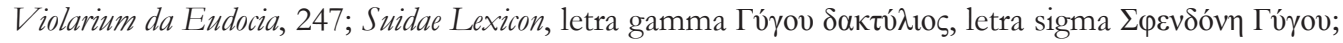
Anthologiae Graecae, Appendix, Epigrammata demonstrativa 253. Os próximos serão citados a partir do Paroemiographi Graeci editado por Leutsch \& Schneidewin, volume I: Diogenianus, 3.99; Gregorius Cyprius, 2.5; volume II: Diogenianus, 2.20; Greg. Cyp., 2.58; Apostolius, 5.71; Macarius, 3.9.

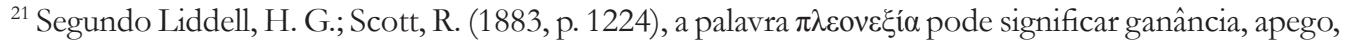
arrogância, vantagem, abundância. De acordo com Chantraine (1979, p. 913), a palavra pertence a

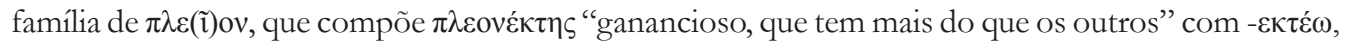

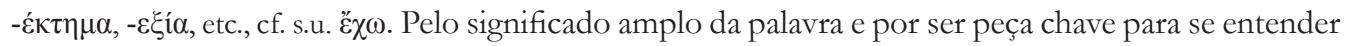


Com o intuito de examinar melhor o que se diz, Gláucon distinguirá os gêneros de vida pela separação de cada um das suas respectivas aparências (dóxai).

Começando pelo injusto, Gláucon pretende demonstrar como é possível para um homem se tornar um tirano sem o uso de um artefato mágico. Ou seja, ele quer demonstrar como sair da impossibilidade da magia do anel para a sua possibilidade. Para isso, irá se utilizar de uma arte capaz de permitir a construção dessa invisibilidade necessária para se agir injustamente. Dessa forma, um homem só poderia agir pela injustiça se pudesse ocultar aos

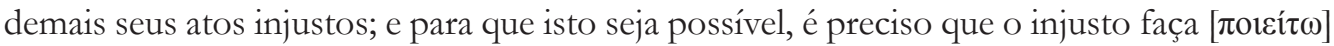

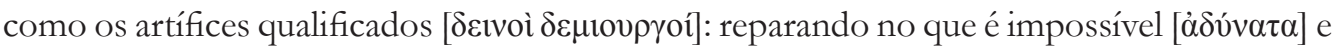

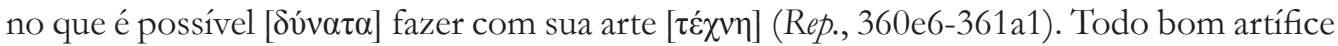
(demiourgós) tem uma arte (tékhnê) que produz (poieîn), com a capacidade (dýnamis) que lhe foi concedida, uma utilidade (ōphelía). Devemos aqui analisar estes elementos fornecidos pelo argumento. O demiourgós é o agente de uma tékhnè, ou seja, ele é aquele que sabe como fazer (poiên) uma arte. Cada arte se diferencia pela sua dýnamis (Rep., 346a), é ela que vai dar o caráter específico para que cada uma possa produzir a sua utilidade. A utilidade é algo que sempre vem junto da arte como um produto necessário desta. Dessa forma, podemos entender que a essência de uma arte está na utilidade que ela produz. ${ }^{22}$ Mas para saber exatamente o que deve fazer, lidando bem com a sua arte, o artífice deve ser hábil em saber qual o limite de sua capacidade. De acordo com Hipócrates:

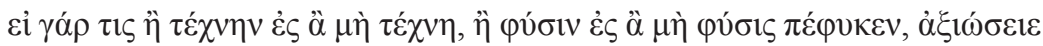

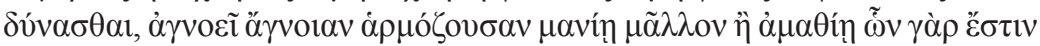

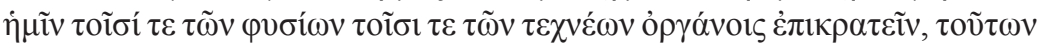

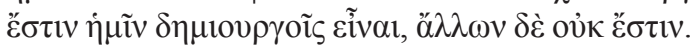

Se um homem demanda de uma arte uma capacidade sobre o que não pertence à arte, ou da natureza uma capacidade sobre o que não pertence à natureza, sua ignorância é mais aliada à loucura que falta de conhecimento. Nos casos onde nós podemos ter o domínio sobre o meio proporcionado pela constituição natural ou pela arte, aí nós podemos ser artífices, mas nada mais que isso (Sobre a Arte, VIII, 10-16). ${ }^{23}$

O bom artífice é aquele que tem pleno domínio sobre a sua arte e produz com acuidade a sua utilidade, pois sabe lidar com a sua dýnamis, não tentando em momento algum ultrapassar o limite que lhe foi dado pelo saber que adquiriu. Será essa regra, que permite aos deinoi demiourgoí agirem no limite da sua dýnamis, a mesma na qual o injusto irá se basear

o tipo de desejo dos polloí, preferimos pela sua transliteração e não pela tradução. Quando utilizamos a palavra, é no sentido de 'desejo de ter mais do que os outros'.

${ }^{22}$ Balansard (2001, p. 60); “A tékhnnè [...] não se define, nem é identificada, por seu érgon, mas por seu objeto. O érgon não diz a essência da tékhnè, mas o benefício (utilidade) que é retirado".

${ }^{23}$ Utilizamos a edição estabelecida por Jones (1981). A tradução é baseada na de Jones. 
para determinar o que é possível a ele fazer e o que deve saber se quiser ser completamente

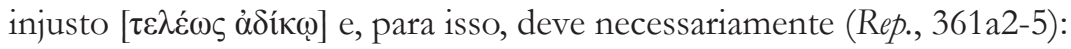

(1) ter seus atos injustos ocultos $[\lambda \alpha \nu \theta \alpha v \varepsilon ́ \tau \omega] \mathrm{e}$

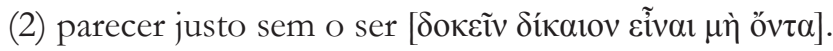

Essas são capacidades necessárias para se ser completamente injusto, sendo que estas nada mais são do que uma única dýnamis, sendo esta a mesma do anel de Gyges. Dessa forma, o anel simboliza tais capacidades necessárias que permitem àquele que assim agir não ser punido por seus atos injustos. Mas tais capacidades são conseguidas por um conhecimento, um saber que permita ao injusto produzir essa dýnamis, e para que esta seja produzida, o injusto deve desenvolver as seguintes habilidades (Rep., 361b2-4):

(1) persuadir [ $\pi \varepsilon i ́ \theta \varepsilon v v]$ para reparar algum erro; e

(2) exercer a violência [ $\beta i \alpha ́ \sigma \alpha \sigma \theta \alpha 1]$ caso alguma de suas injustiças seja denunciada.

A retórica, arte persuasiva de bem falar, poderia permitir que o engano, provocado pela sua arte, criasse uma aparência do que não se é, dando àqueles que não são justos a aparência de justiça, pois, como bem nos lembra Adimanto,

$\tau$

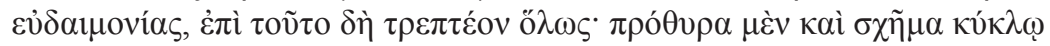

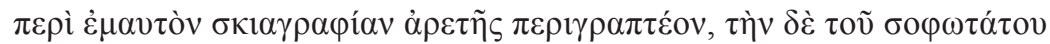

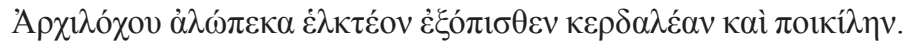

a aparência, como me demonstram os sábios, subjuga a verdade e é senhora da felicidade, sendo para esse lado que devemos nos voltar por completo. Tenho de traçar em círculo à minha volta, como uma fachada e frontaria, uma sombra da virtude, e arrastar atrás de mim a raposa matreira e astuciosa do muito sapiente Arquíloco (Rep., 365c1-6). ${ }^{24}$

Adimanto, nessa passagem, coloca ao argumento um pedaço do que os ditos sábios [oi бo甲oi] pensam com relação à verdade. Os sábios aqui em questão seriam os poetas que defendem a justiça por sua aparência e as recompensas advindas desta, mas não por si mesma e, como exemplo de sábio, ele citará Arquíloco com sua astuta raposa. Os poetas são aqueles que diretamente influenciam os polloí, com sua poesia, dando estes a educação desde a infância. Segundo dizem, a verdade está subjugada pela aparência e, portanto, é a aparência que devemos seguir por inteiro se quisermos ser felizes, pois não se é prejudicado pela aparência, mas pela verdade. Aquele que sabe melhor manipular a dóxa é aquele que pode tirar vantagens sobre os outros, ocultando a verdade que se encontra por debaixo da dóxa.

A felicidade é o que está o tempo todo em questão quando tratamos de qual o melhor gênero de vida a ser escolhido. Se a aparência permite que tracemos a nossa volta

\footnotetext{
${ }^{24}$ As mudanças na tradução são nossas.
} 


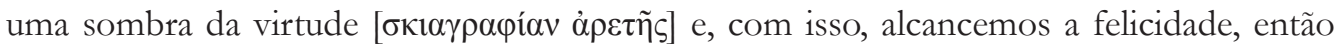
devemos escolher como modo de vida aquele que melhor permite vivermos pela aparência. Mas viver dessa forma e passar despercebido não é tarefa fácil e, por isso,

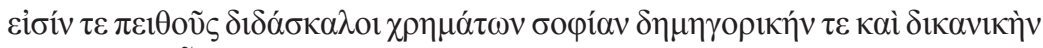

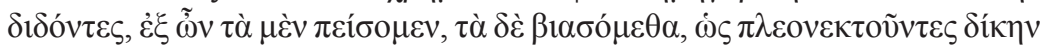

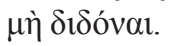

temos mestres de persuasão, para nos darem a ciência das arengas e do foro, com cujos recursos havemos, ora de persuadir, ora de exercer a violência, de tal maneira que satisfaremos as nossas ambições, sem termos de pagar à justiça (Rep., 365d3-6).

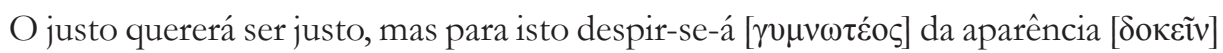

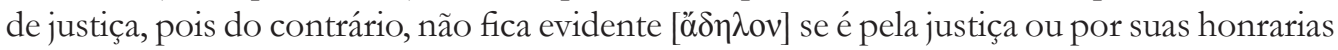
e dádivas que se quer sê-lo (Rep., 361c). Nada sobra ao justo senão a justiça e sem cometer injustiça alguma, tenha ele a aparência de máxima injustiça, a fim de pôr à prova em relação à justiça, por não se abrandar a vergar-se ao peso da má fama e suas consequências (Rep., 361c5-8). Ao adquirir a dóxa da injustiça, o justo receberá todas as penas referentes a esta dóxa, e por isso,

$\mu \alpha \sigma \tau \imath \gamma \omega ́ \sigma \varepsilon \tau \alpha l, \sigma \tau \rho \varepsilon \beta \lambda \omega ́ \sigma \varepsilon \tau \alpha l, \delta \varepsilon \delta \eta ் \sigma \varepsilon \tau \alpha l, ~ \dot{\varepsilon} \kappa \kappa \alpha v \theta \eta ́ \sigma \varepsilon \tau \alpha \iota \tau \omega ̉ \varphi \theta \alpha \lambda \mu \omega ́$,

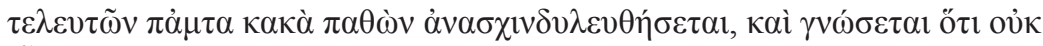

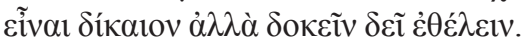

será chicoteado, torturado, feito prisioneiro, queimar-lhe-ão os olhos e, por último, depois de ter sofrido toda a espécie males, será empalado e compreenderá que se deve querer, não ser justo, mas parecê-lo (Rep., 361e4$362 \mathrm{a} 2)$.

Já o completamente injusto tem a dóxa da justiça e com essa se beneficia. Se ser completamente injusto traz consigo a aparência de justiça, então, esta não é essencial ao justo e pode dele ser separada. Neste tipo de relação, ser não é o mesmo que parecer e, dessa maneira, tudo que parece pode ser algo retirável e manipulável. Se Gláucon está distinguindo o justo do injusto retirando-lhes todas as recompensas, a aparência e qualquer tipo de coisa que possa vir à parte deles próprios, deixando apenas a essência para julgar o melhor tipo de vida, então, temos a aparência de justiça como algo à parte de ser justo e, portanto, retirável deste, mas para o injusto tal aparência de justiça deve fazer parte da sua descrição, se este quiser ser verdadeiramente injusto. É nesse ponto que entra o trabalho da demiourgía que permite ao injusto, como um hábil demiourgós, usar da sua arte para produzir a sua invisibilidade: deixa de parecer injusto, ocultando a sua própria dóxa, para aderir a dóxa da justiça e, assim, parecer justo e para poder se beneficiar com as recompensas e honras deste.

Outro ponto a se notar é que, mesmo depois de se retirar tudo que vem à parte tanto da justiça quanto da injustiça, é ainda possível perguntar qual a vida mais feliz, sendo esta pergunta o motivo de toda a separação feita entre justo e injusto. Dessa forma, se a 
felicidade estiver relacionada com a aparência e com as recompensas da justiça, então, ela também estará ligada à injustiça por si mesma, já que esta possui, em sua forma completa, a aparência de justiça e todas as recompensas relacionadas com esta. Logo, para os polloí, ser essencialmente injusto é ter a aparência de justo e, com isto, adquire todas as vantagens de se parecer justo sem precisar sê-lo, sendo estas (Rep., 362b2-c6):

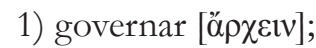

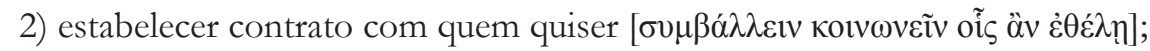

3) levar vantagem dos inimigos [ $\pi \lambda \varepsilon 0 v \varepsilon \kappa \tau \varepsilon \tilde{v} \tau \tilde{\omega} v \dot{\varepsilon} \chi \theta \rho \tilde{v} v]$;

4) enriquecer [ $\left[\pi \lambda \lambda_{0 v \tau \varepsilon i v]}\right.$;

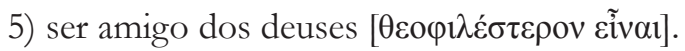

De acordo com os polloí, o que parece estar sendo posto em xeque aqui não é o justo por si mesmo apenas, mas a possibilidade desse homem justo existir, pois se a natureza humana é voltada para a pleonexía e tem como um bem o ato de cometer injustiças para sua satisfação pessoal, então, o justo por si mesmo não poderia existir e, se existisse, não poderia ser feliz, já que a justiça por si mesma é penosa e não desejada como um bem por si mesma. Dessa forma, ainda segundo o parecer deles, a injustiça no seu mais completo estado é o tipo de vida mais feliz e, assim, não pode estar a felicidade relacionada à justiça por si mesma, mas somente às suas recompensas, pois são estas que trazem os benefícios da vida justa.

Segundo pensam os polloí, aquele que for completamente injusto será feliz, e poderá unir os benefícios da injustiça com os benefícios da justiça. No entanto, como nos lembra Adimanto, "não é fácil passar sempre despercebido quem é mau" (Rep., 365c7), e para se beneficiar da dóxa da justiça e não receber punição por seus atos injustos, o injusto deve fazer o árduo trabalho de um hábil artífice e, assim, conseguir enganar e persuadir de que se é justo, já que, "não há nada de grandioso que não tenha dificuldades" (Rep., 365c8). Isso levaria a dizer que a dýnamis da injustiça quando existe na alma produz uma pena, mas tem uma utilidade que permite a esta alma ser feliz pelos bens que adquire, segundo os polloí.

Para entendermos que tipo de homem é esse que temos como resultado da injustiça na alma, vamos a partir de agora examiná-lo minuciosamente. No Livro VIII, Sócrates irá iniciar a diferenciação entre desejos necessários e aqueles que não são necessários [ $\tau$ ás $\tau \varepsilon$

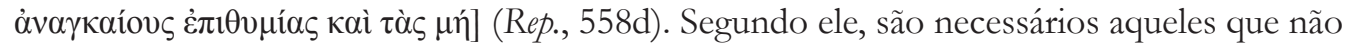

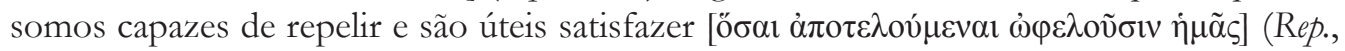
558e); não necessários são aqueles de que podemos nos libertar (Rep., 559a). Uma relação entre necessidade e utilidade é estabelecida nessa passagem, fazendo com que todos os desejos necessários sejam úteis, mas o mesmo não pode ser dito dos desejos não necessários. Serão justamente estes que irão preocupar Sócrates com relação ao tirano, pois a tirania vem do excesso, excesso este que vem do ambiente democrático e que acaba por aprisionar a si mesmos: 


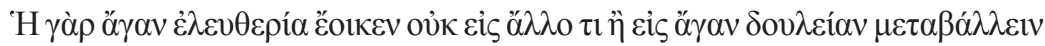

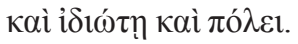

A liberdade em excesso, portanto, não conduz a mais nada que não seja a escravatura em excesso, quer para o indivíduo, quer para a pólis (Rep., 564a). ${ }^{25}$

O excesso [á $\gamma \alpha v]$, aqui colocado, pode estar indicando uma desmedida por oposição à célebre frase do oráculo de Delfos $\mu \eta \delta \varepsilon \dot{\varepsilon} v a$ ó $\alpha v$. Seu sentido pode se aproximar ao da pleonexía colocada no Livro II, para indicar o ponto de mudança entre democracia e tirania dentro do indivíduo e da pólis. No Livro IX, Sócrates irá iniciar uma análise do tirano a partir do desejo. Segundo ele,

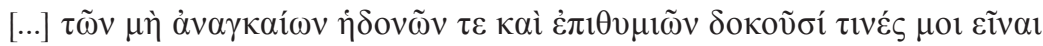

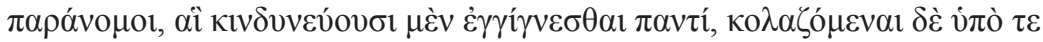

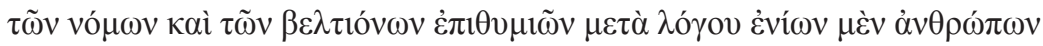

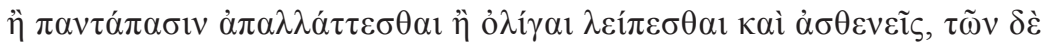

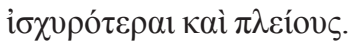

[...] entre prazeres e desejos não necessários, há alguns que parecem ilegítimos, que provavelmente são inatos em toda a gente, mas, se forem castigados pelas leis e pelos desejos melhores, com o auxílio da razão, em alguns homens, ou se dá a libertação total deles ou que restam são poucos e débeis; ao passo que em outros se tornam mais fortes e mais numerosos (Rep., 571b3-c1).

Assim como,

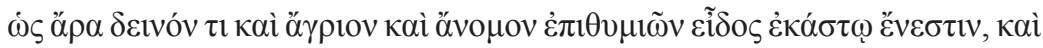

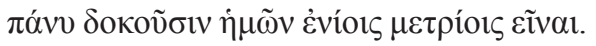

existe em cada um de nós uma espécie de desejos terrível, selvagem e sem lei, mesmo nos poucos de entre nós que parecem ser comedidos (Rep., 572b3-5).

Serão esses desejos desnecessários associados à desmedida [üßpıc] (Rep., 572c7) o que irá permitir que a parte mais baixa da alma a governe e, por esta deturpação, se chamará

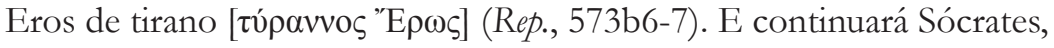

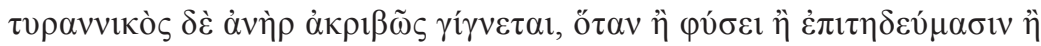

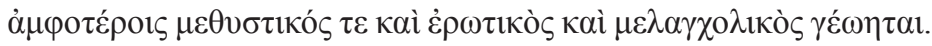

o homem se torna rigorosamente um tirano, quando por natureza, ou por hábito, ou pelos dois motivos, se torna ébrio, apaixonado e irascível (Rep., $573 \mathrm{c} 7-9)$.

Ao que tudo indica, poder e riqueza em excesso são objetos de desejo do tirano, desejo este sem fim. Para os polloí, o bem estaria em se cometer injustiça, e um homem que

${ }^{25}$ A mudança na tradução é nossa. 
estivesse livre das convenções e leis por algum motivo, seria conduzido por sua epithymía a escolher o caminho que naturalmente é próprio do homem: a pleonexía. Essa vontade de ter sem fim já aparecia em Arquíloco (Cf. Fr. 19W) com a palavra zêlos associada à cobiça e inveja, assim como também temos a palavra polýkhrysos para falar do muito ouro ou, de maneira geral, das riquezas de Gyges, que podem, na narrativa de Gláucon, ser resumidas no anel de ouro (khrysoûn daktýlion). A palavra eréo em Arquíloco pode entrar em conexão com a epithymía em Gláucon, sendo que aquela, em Arquíloco, está diretamente relacionada com a megále tyrannís. A relação da tirania com os desejos eróticos pode ser vista também em Platão no Livro IX, conforme foi observado acima. A tirania parece estar relacionada com este tipo de grandeza de desejos, vontade de poder e riqueza. Esse desejo exacerbado leva à inveja ao poder dos deuses, deuses estes que não podem ainda ser definidos como bons e causadores somente de bens, como Platão irá apresentá-los pelo argumento do Livro II (Rep., 379a et seq), mas devem ser considerados segundo a religião grega e a poesia que os canta: invejosos, capazes de agir em benefício próprio e de seus aliados, tomando para si aquilo que desejam e podendo se unir a quem os apetecer. Para o homem que pudesse agir desta maneira seria considerado por todos os outros com igual a um deus [iøó $\theta \varepsilon o s]$ (360c3). A narrativa contada por Gláucon mostra Gyges saindo da situação de pastor para se tornar um governante através de um recurso mágico: um anel de ouro que o permite ficar invisível e visível a sua vontade. A dýnamis do anel faz com que Gyges aja da maneira como quiser, permitindo que ele se liberte do contrato que o faz agir de acordo com o nómos, para poder agir de acordo com a sua phýsis. Vive apenas para os seus desejos e prazeres. Ora, viver desta forma, segundo o argumento dos polloí, é ser um isótheos, relação esta que é estabelecida pela tragédia na passagem 568b da República, que, segundo Sócrates, faz um elogio do tirano como sendo um isótheos, isto porque o tirano é aquele que vive apenas para os seus desejos e ambições. Esse tipo de construção - tirania e deuses - é algo que podemos verificar em Arquíloco, que aproxima os termos theôn érga com a própria tirania, e os mesmos se aproximam de Gyges.

Como já pudemos observar, a tradição lírica tem em conta a figura de Gyges como um tirano, rico em ouro, senhor de homens que se iguala a um deus em seus atos e desejo de poder. Ser completamente injusto é ser tirano, e, para que isto possa se realizar, o injusto deve agir no limite de sua dýnamis, sabendo separar o que ele pode do que não pode fazer. A dýnamis do anel é o que permite Gyges agir como um tirano, pois o torna capaz de ocultar seus atos injustos dos demais. Se um homem pudesse separar adequadamente o que pode do que não pode fazer e soubesse o que deve ocultar em suas ações dentro das habilidades que competem ao verdadeiro injusto, então tal homem poderia atingir a tirania como a forma de governo que compete a tal homem e teria uma vida feliz. O fato de poder estar visível e invisível quando quiser faz da tirania o governo do injusto, que comete suas injustiças ocultamente, para obter aquilo que seu desejo indica como um bem, e parece justo quando visível está, enganando todos os demais que por ele são governados de que seu governo é bom e justo. Tal fato faz de Gyges o tirano por excelência. 


\section{REFERÊNCIAS}

ADAM, James. The Republic of Plato, v. 1. Edição de J. Adam. Cambridge: Cambridge University Press, 1979.

ADRADOS, F. R. Líricos Griegos: Elegiacosy Yambógrafos Arcaicos, v.1. Texto traduzido por F. R. Adrados. Madrid: Consejo Superior de Investigaciones Científicas, 1990a.

ADRADOS, F. R. Líricos Griegos: Elegiacosy Yambógrafos Arcaicos, v.2. Texto traduzido por F. R. Adrados. Madrid: Consejo Superior de Investigaciones Científicas, 1990b.

ALBERTUS, I; SCHMIDT, M. Hesychii Alexandrini Lexicon Post Ioannem Albertum recensuit Mauricius Schmidt. Volumen Primum. Ienae: Sumptibus Frederici Maukii, 1858.

AST, F. Platonis quae exstant Opera. Tomus IV, Politiae Lib. I-VIII. Lipsiae: Libraria Weidmannia, 1822.

BALANSARD, A. Technè dans les Dialogues de Platon. L'empreinte de la sophistique. Sankt Augustin: Academia Verlag, 2001.

BERGK, T. Poetae Lyrici, v.2. Poetas elegiacos et Iambographos Continens. Lipsiae: Aedibus B. G. Teubneri, 1882. (4 ed.).

BOLLING, G. M. Kandaules. Language, v. 3, n. 1, p. 15-18, 1927.

BURNET, J. Platonis Opera, recognovit brevique adnotatione critica instrvxit: Ioannes Burnet, Tomvs IV. Oxford: Oxford University Press, 1902.

BURNET, J. Platonica II. The Classical Review, v. 19, n. 2, p. 99-101, 1905.

CAMPBELL, D. A. Greek Lyric. With English translated by D. A. Campbell. Cambridge, Mass.: Harvard University Press; London: W. Heinemann, 1982-1993. 5v.

CHANTRAINE, P. Dictionnaire étymologique de la langue grecque: Histoire des mots, tomes I-IV. Paris: Éditions Klincksieck, 1968-80.

FAUTH, W. Zum Motivbestand der Platonischen Gygeslegende. Rheinisches Museum für Philologie, v.113, p. 1-42, 1970.

FERREIRA, J. R.; SILVA, M. F. Histórias. Livro 1. Tradução e Notas de José Ribeiro Ferreira e Maria de Fátima Silva. Lisboa: Edições 70, 2002.

FRAZER, Sir James George. Pausanias's Description of Greece: Commentary on Books II-V: Corinth, Laconia, Messenia, Elis. London: Macmillan and co., 1913.

GELZER, H. Das Zeitalter des Gyges. Rheinisches Museum für Philologie, v. 30, p. 230-268, 1875. GERBER, D. E. (ed.) A Companion to the Greek Lyric Poets. Leiden; New York; Köln: Brill, 1997. GERBER, D. E. Greek Iambic Poetry. Edited and translated by D. E. Gerber. Cambridge, Mass.: Harvard University Press, 1999a. 
GERBER, D. E. Greek Elegiac Poetry. Edited and translated by D. E. Gerber. Cambridge, Mass.: Harvard University Press, 1999b.

HANFMANN, G. M. A. Lydiaka. Harvard Studies in Classical Philology, v. 63, p. 65-88, 1948.

HUDE, C. Herodoti Historiae Tomvs I. Recognovit brevique adnotatione critica instrvxit: Carolvs Hude. Oxford: Oxford University Press, 1927.

JACOBY, F. The Date of Archilochus. Classical Quarterly, v. 35, n.3, p. 97-109, jul.-oct. 1941.

JONES, H. L. Strabo Geography. Books 13-14. Edição de H. L. Jones. Cambridge, Mass.: Harvard University Press; London: William Heinemann, 1924.

JONES, W. H. S. Hippocrates. With an English translation by W. H. S. Jones. The Loeb Classical Library, v. 2, “The Art”. Cambridge, Mass.; London: Harvard University Press, 1981.

JONES, W. Finger-Ring Lore. London: Chatto and Windus, Piccadilly, 1877.

JOWETT, B.; CAMPBELL, L. Plato's Republic. The Greek Text, v. III: Notes. Oxford: The Clarendon Press, 1894.

KROLL, G. Procli Diadochi in Platonis Rem Publicam Comentarii, v. II. Edidit G. Kroll. Lipsiae: Aedibvs B. G. Tevbneri, 1901.

LEUTSCH, E. L.; SCHNEIDEWIN, F. G. Paroemiographi Graeci. Edição de Leutsch \& Schneidewin, 2.v. Gottingae: Sumptus Fecit Libraria Dieterichiana, 1939-51.

LIDDELL, H. G.; SCOT'T, R. Greek-English Lexicon. 2 ed. New York: Harper \& Brothers, 1883.

MENEZES, L. M. B. R. Nova Interpretação da Passagem 359d da República de Platão. Kriterion, v. 125, p. 29-39, 2012.

MILLER, W. Cicero de Officiis. With English translation by W. Miller. London: William Heinemann; New York: G.P. Putnam’s Sons, 1928.

MÜLLER, C. Fragmenta Historicum Graecorum, vol. III. Paris: Editore Ambrosio Firmin Didot, 1849.

PATON, W. R. The Greek Anthology. v. 2 e 4. With English translated by W. R. Paton. London: William Heinemann; New York: G.P. Putnam’s Sons, 1918-9.

PEDLEY, J. G. Ancient Literary Sources on Sardis. Cambridge, Mass.: Harvard University Press, 1972.

PEDLEY, J. G. Sardis in the age of Croesus. Norman: University of Oklahoma Press, 1968.

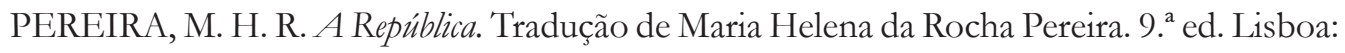
Fundação Calouste Gulbenkian, 2001.

ROSS, W. D. Aristotelis Ars Rhetorica. Edição de W. D. Ross. Oxford: Clarendon Press, 1959. 
SCHNEIDER, C. E. C. Platonis Opera Graece., v. I. Lipsiae, 1830.

SLINGS, S. R. Critical Notes on Plato's Politeia II. Mnemosyne, v. 17, fasc. 3-4, p. 381-383, 1989.

SLINGS, S. R. Platonis Rempublicam, recognovit brevique adnotatione critica instrvxit: S. R. Slings. Oxford: Oxford University Press, 2003.

SMITH, K. F. The Tale of Gyges and the King of Lydia. The American Journal of Philology, v. 23, n. 3, p. 261-282, 1902a.

SMITH, K. F. The Tale of Gyges and the King of Lydia. The American Journal of Philology, v. 23, n. 4, p. 361-387, 1902 b.

SNELL, B. A Descoberta do Espírito. Tradução A. Morão. Lisboa: Edições 70, 1992.

SPALINGER, Anthony J. The Date of the Death of Gyges and its Historical Implications. Journal of the American Oriental Society, v. 98, n. 4, p. 400-409, Oct.-Dec., 1978.

STALLBAUM, G. Platonis Dialogos Selectos. Recensuit et commentariis in usum scholarum instruxit Godofredus Stallbaum. v. III.1. Politiae I-V. Gothae et Erfordiae, 1829.

STEIN, H. Herodotos. v. I. Berlim: Weidmannsche Buchhandlung, 1883.

STURTZ, F. G. Etymologicum Graecae Lynguae Gudianum. Qvas digessit et vna cvm svis edidit F. G. Stvrtzivs. Lipsiae: Weigel, 1818.

SUIDAE LEXICON GRAECI et LATINE. Typis Academicis, $1705.3 \mathrm{v}$.

URE, P. N. The Origin of Tyranny. Cambridge: Cambridge University Press, 1922.

WEST, M. L. Iambi et Elegi Graeci Ante Alexandrum Cantati. (Editio Altera). Edidit M. L. West. Oxford: Oxford University Press, 1971.

WEST, M. L. Studies in Greek Elegy and Iambus. Berlin: Walter de Gruyter \& Co., 1974.

WEST, M. L. Carmina Anacreontea. Edidit M. L. West. Stutgardiae; Lipsiae: Teubner, 1993 [1984].

WEST, M. L. Greek Lyric Poetry. Oxford; New York: Oxford University Press, 1993.

Recebido em: 19 de março de 2017

Aprovado em: 4 de abril de 2017 